\title{
The Performance of Resistance Progressive Collapse Analysis for High-Rise Frame-Shear Structure Based on OpenSees
}

\author{
Qiang Zhang and Yaozhuang Li \\ Institute of Disaster Prevention Science and Safety Technology, Central South University, Changsha 410128, China \\ Correspondence should be addressed to Yaozhuang Li; 441894855@qq.com
}

Received 21 January 2017; Accepted 20 March 2017; Published 4 April 2017

Academic Editor: Aly-Mousaad Aly

Copyright (c) 2017 Qiang Zhang and Yaozhuang Li. This is an open access article distributed under the Creative Commons Attribution License, which permits unrestricted use, distribution, and reproduction in any medium, provided the original work is properly cited.

\begin{abstract}
A finite element model (FEM) of frame-shear structure was constructed using OpenSees program based on the nonlinear flexibility theory and multi-vertical-line theory that considered bending-shear coupling, and its progressive collapse resistance under abnormal conditions was analyzed. Flexibility-based method for modeling shear wall finite element and multi-verticalline element (SFI-MVLEM) was proposed. Method of deleting failure component elements was presented, as well as the model solving algorithm. The FEM was validated by the completed structure test. On these bases, 3 groups of typical frame-shear structure systems were designed to perform nonlinear dynamic collapse analysis under different initial failure conditions, in order to study the impact of the number of floors and earthquake resistant design on the progressive collapse resistance of frame-shear structures. Analysis results showed that, at initial failure of frame column, the residual shear wall element can well complete the internal force redistribution of structure to provide alternative force transmission path, thereby forming antiprogressive collapse force. In the case of initial failure of shear wall, C-shaped shear wall can form alternative path to diminish the vertical deformation of frame-shear structures. Final comparison shows that the structural seismic design can effectively improve their anticollapse performance.
\end{abstract}

\section{Introduction}

Progressive collapse of building structures refers to the horizontal and vertical sequential damage of structures led by local failure caused by explosion, terrorist attacks, and other accidents, which results in collapse of overall structures or large-scale collapse that is disproportionate to the initial damage [1]. Progressive collapse of structures severely harms the public safety and people's lives and property. Internationally, research on the progressive collapse of structures began with the British Ronan Point apartment collapse in 1968 initiated by gas explosion. In 2001, the US World Trade Center collapsed as a result of "911" terrorist attack, which drew the attention of engineering and academic circles $[2,3]$. After years of scientific research and exploration, various countries have developed comprehensive antiprogressive collapse design codes. Representative ones are the US GSA and DoD guidelines. Meanwhile, China also officially released the collapse resistance code in 2015, the Code for Anticollapse Design of Building Structures. Taking a general view of the codes of various countries, the antiprogressive collapse design of highrise structure focuses mainly on enhancing the reinforcement within beams, increasing the bending capacity of beam ends, and strengthening the role of beam mechanism, while exerting the axial tensile catenary action of rebar, in order to enhance the overall structural stability. For now, in terms of analytical methods, the most commonly used method of analyzing progressive collapse resistance is the linear static alternate path method, while the most accurate method is the nonlinear dynamic alternate path method [3-7].

Aside from the research findings in design codes and progressive collapse resistance guidelines, scholars from various countries have also made some progressive collapse in structural testing and numerical simulation in recent years. For example, with respect to collapse testing, Yi et al. [8] conducted a collapse test on a plane frame through quasistatic demolition test to determine the stress process of the test frame and the stress transformation mechanism. On this basis, Li et al. [9] carried out a collapse test on a plane frame infill wall to determine the contribution of infill wall within 
the frame to the collapse resistance and collapse process of frame infill wall. With respect to spatial structure testing, Wang et al. [10] used a quasistatic approach to complete a series of progressive collapse tests on dual-layer bidirectional $\mathrm{RC}$ frame. They analyzed the transformation and stress mechanisms in each collapse stage of the space frame and put forward the lateral deformation calculating method as well as structural damage model. In terms of numerical calculation, Zhang and Liu [11] proposed several major challenges in solving the progressive collapse of structures: large geometric displacement and deformation, discontinuous displacement field, and collision effect between collapsed elements. Based on the energy balance algorithm, Vlassis et al. [12] constructed a theoretical framework for analyzing the progressive collapse resistance of RC frame structures. On this basis, $\mathrm{Li}$ et al. [13] derived the demand relationship between linear and nonlinear resistance of beam and catenary mechanisms in the collapse process of frame structures. Regarding the finite element programming computation, Wang et al. [14] built a 12-story frame structure based on the ABAQUS FEA software for the nonlinear analysis of progressive collapse. In summary, despite many existing antiprogressive collapse theoretical systems and finite element programming computation methods for structures, most of them are for RC frame structures. Few studies have investigated the contribution of shear wall to the antiprogressive collapse in the RC frameshear wall structures. In addition, there is little research on the effect of seismic design on anticollapse performance of structures despite the widespread concern about antiprogressive collapse capability of high-rise structures. In view of this, this paper discusses the effect of seismic design.

A typical frame-shear building structure (6-degree seismic design) is designed herein according to the Chinese Code for Design of Concrete Structures (GB 50010-2010) based on OpenSees finite element program. Using the designed structure, an analysis is made on the effect of number of stories on progressive collapse resistance of frame-shear structure. To consider the effect of seismic design on the structural antiprogressive collapse performance, the frame-shear structure is subjected to 8-degree seismic design in accordance with the Code for Seismic Design of Buildings (GB 50011-2010), as well as to progressive collapse analysis. Meanwhile, finite element model is constructed with flexibility method-based fiber beam elements and novel multi-vertical-line shear wall elements that consider bending-shear coupling. Modeling method of the frame structure is presented and verified by an example. On these bases, alternate path method is employed to perform nonlinear dynamic analysis on the RC frameshear wall structure model. The relevant modeling method and calculation results can provide some references for the antiprogressive collapse analysis of frame-shear structures.

\section{Design Information}

A 15-story RC frame-shear wall structure is designed according to the Code for Design of Concrete Structures (GB 500102010) and the Code for Seismic Design of Structures (GB 500112010) with reference to the structural layout of an actual

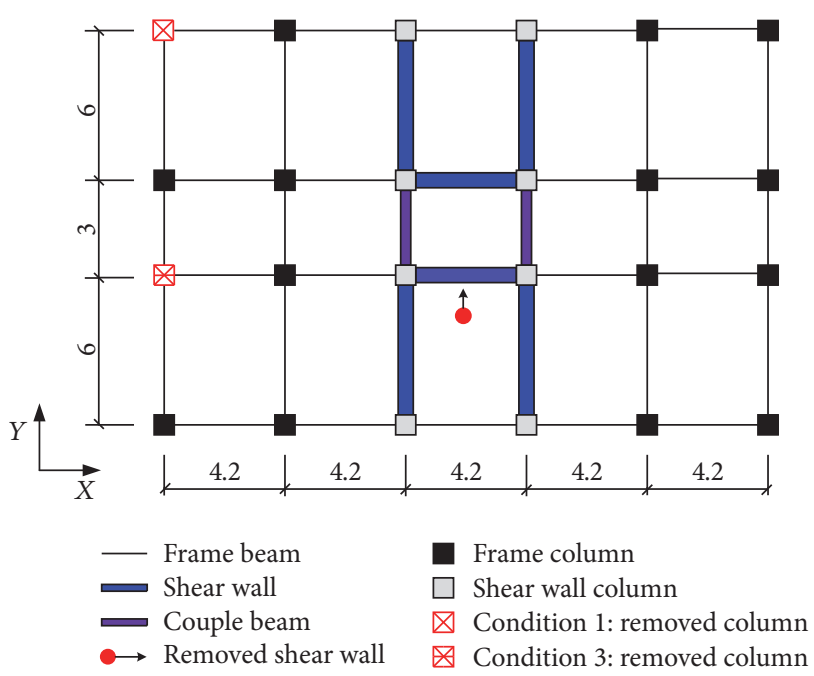

FIGURE 1: Floor plan of the building models (unit: $\mathrm{m}$ ).

project $[15,16]$. The relevant design information is as follows:

(1) Figure 1 presents the planar layout of the structure. The first story is $4.2 \mathrm{~m}$ high, while the remaining stories are $3.6 \mathrm{~m}$ high. Columns have a cross section size of $650 \mathrm{~mm} \times 650 \mathrm{~mm}$, while those for transverse beams ( $X$ direction) and longitudinal beams ( $Y$ direction) are $300 \mathrm{~mm} \times 500 \mathrm{~mm}$ and $350 \mathrm{~mm} \times 700 \mathrm{~mm}$, respectively. Floor thickness is $120 \mathrm{~mm}$, while column feet are assumed to be fixed to the floor. In terms of materials, concrete used for shear walls and columns has a strength grade of $\mathrm{C} 40$, while that used for plates and beams has a strength grade of C30. Longitudinal rebar pieces of constraint elements at the edge of shear walls are the same in grade as those of columns, which are HRB400. Besides, type of longitudinal rebar of beams is selected as HRB335, whereas type of stirrup material is HPB235. Table 1 displays the material parameters of the structural members in these buildings.

(2) Load information: floor dead load is $5.0 \mathrm{kN} / \mathrm{m}^{2}$ and live load $2.0 \mathrm{kN} / \mathrm{m}^{2}$. Roof dead load is $7.5 \mathrm{kN} / \mathrm{m}^{2}$ and live load $0.5 \mathrm{kN} / \mathrm{m}^{2}$, while surface roughness is set as category C.

(3) Seismic design information: type of soil in the construction site is set as type II. Besides, seismic fortification intensity is 6 degrees, and seismic grade of shear walls and frames is grade 2 . To consider the effect of seismic design on the structural antiprogressive collapse, the frame-shear structure is subjected to 8-degree seismic design, while other design information remains unchanged. The corresponding design peak ground acceleration (PGA) with a $10 \%$ probability of exceedance in 50 years equals 0.05 and $0.20 \mathrm{~g}$, in which $g$ is the acceleration of gravity. Note that because of different requirements of the maximum axial force ratios specified in the Chinese seismic 
TABLE 1: Parameters of structural material.

\begin{tabular}{lccc}
\hline Item name & Beams & Columns & Shear walls \\
\hline Concrete & C30 $\left(f_{c}=20 \mathrm{MPa}\right)$ & $\mathrm{C} 40\left(f_{c}=26.8 \mathrm{MPa}\right)$ & $\mathrm{C} 40\left(f_{c}=26.8 \mathrm{MPa}\right)$ \\
Longitudinal reinforcing steel & HRB335 & HRB400 \\
Hoop reinforcing steel & $\left(f_{y}=335 \mathrm{MPa}\right)$ & $\left(f_{y}=400 \mathrm{MPa}\right)$ \\
\end{tabular}

TABLE 2: Dynamic properties of the structure.

\begin{tabular}{lccc}
\hline Item name & & 6-degree & 8-degree \\
\hline & $\mathrm{T}_{1}$ (1st-order translation in X direction) & 1.5 & 1.05 \\
Vibration periods $(\mathrm{s})$ & $\mathrm{T}_{2}$ (1st-order translation in $Y$ direction) & 1.5 & 1.05 \\
& $\mathrm{~T}_{3}$ (1st-order torsion) & 1.24 & 0.88 \\
Self-weight $(\mathrm{t})$ & & 3250 & 3480 \\
\hline
\end{tabular}

design code, the steel quantity in 8-degree seismic design is large than that in 6-degree seismic design. Specifically, the maximum axial force ratio for the design intensity of 6-degree is 0.9 , whereas that for the design intensity of 8 -degree is 0.75 . And steel dosage also results in different self-weights in these buildings. The basic dynamic properties of the frame-shear wall structures are given in Table 2.

To consider the effects of different number of stories on the progressive collapse resistance of frame-shear structure and to simplify the collapse analysis process, in this paper, 10 -story and 15-story RC frame-shear models are built for separate antiprogressive collapse analyses. To consider the effect of seismic design on the structural anticollapse performance, the frame-shear structure is subjected to 8-degree seismic design and modeling for progressive collapse analysis, followed by comparative analysis of collapse models. In accordance with the provisions of GSA2010 and DoD2010, demolition analysis on key components is needed. To comprehensively analyze the antiprogressive collapse performance of frame-shear structure, the following demolition conditions are designed herein. Regarding the demolition of key columns, corner columns and the short edge column are chosen for removal. Regarding the demolition of shear walls, in accordance with the DoD2010 provisions, load-bearing walls with height greater than twice the story height should be removed in steps, while for those with height less than twice the story height, shear walls can be removed as a whole for the progressive collapse analysis. According to the design information, shear walls of this paper are lower than twice the story height, so shear walls in the center of first floor are chosen for holistic removal. Relevant demolition sites are marked in Figure 1.

In accordance with the DoD2010 provisions, the judging mechanism for progressive collapse failure of structure in this paper is as follows: when the top displacement of removed member exceeds $1 / 5$ of the vertical relative displacement of beam connected to it, the structure is judged as failure, which enters an irreversible collapse process. The frame-shear structure in this paper is symmetrical. Nonlinear dynamic alternate path method is used to analyze the frame-shear model, in order to ensure the accuracy of antiprogressive collapse analysis.

\section{Finite Element Model}

3.1. SFI-MVLEM Element Model for Shear Walls. Multi-vertical-line shear wall element considering bending-shear coupling is developed on the basis of three-vertical-line-element theory. Initially proposed by Japanese scholars [17], the threevertical-line-element model utilizes the axial stiffness by the two external elements and adds a horizontal spring at the position of central line element to simulate the shear response on the RC wall by shifting the neutral axis of wall member. But the defects are that consistent deformation between local springs and central line element is difficult and the height of central line element can hardly be determined, which easily lead to computational difficulty. On this basis, researchers have developed a multi-vertical-line-element theory, where multiple vertical springs are introduced to simulate the axial and bending stiffness of shear walls, and horizontal springs are used at the position of central line element to simulate the shear stiffness, thereby solving the problem of difficulty in consistent deformation. However, shear action cannot be considered for vertical springs, and the contribution of RC material to shear force is neglected, so its use in simulation may lead to computational deviation. Eventually, a multivertical-line element theory considering bending-shear coupling was developed [18], which is based on the fixed-strutangle-model (FSAM) and where a novel RC element is used to replace the vertical fiber element. Bending-shear action and material constitution can directly be considered for a single RC element in the model, and separate stress analysis is possible. Furthermore, interlock behavior of concrete aggregate and dowel action of rebar are modified to improve the computation accuracy of the model. The theoretical schematic diagram is shown Figure 2.

3.2. Flexibility-Based Fiber Line Element for Beam and Column. In the geometric nonlinear analysis of structure's progressive collapse, the actual and assumed displacement fields of line elements like beams and columns differ greatly. So fine 


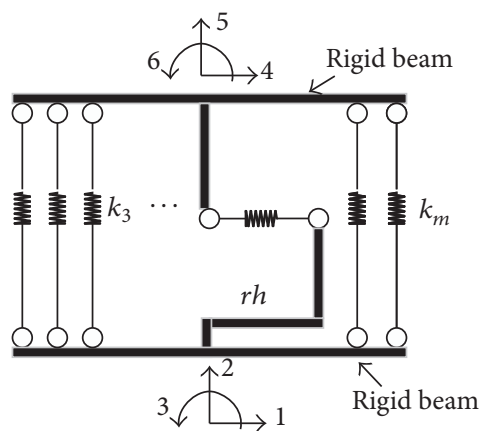

(a)

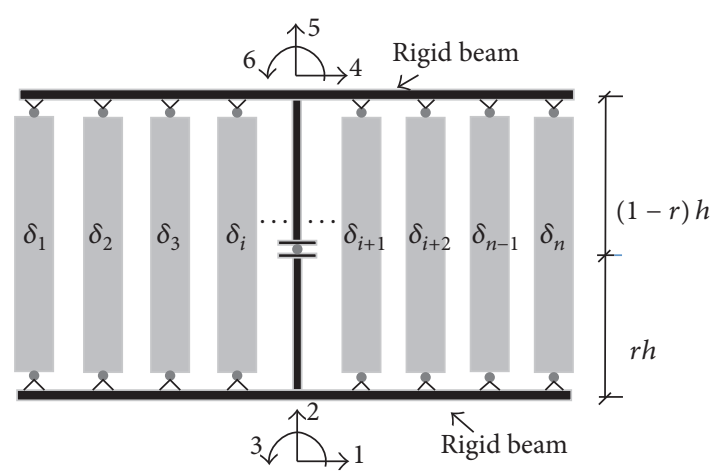

(b)

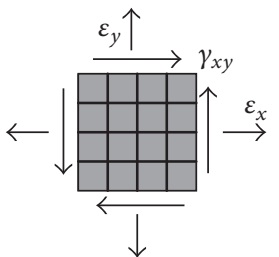

(c)

Figure 2: Element models: (a) MVLEM element; (b) SFI-MVLEM element; (c) RC panel element.

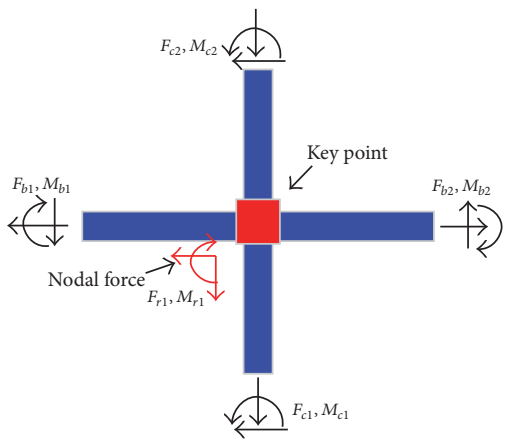

(a) Initial phase

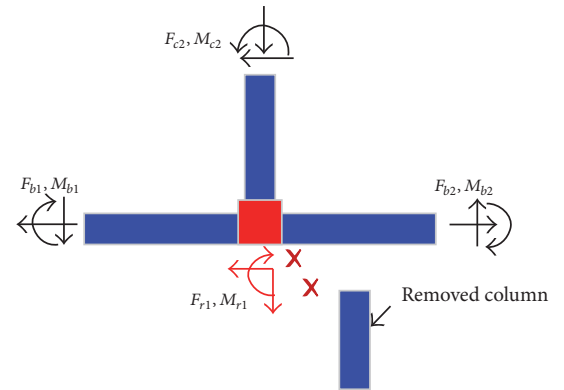

(b) Static internal force stage

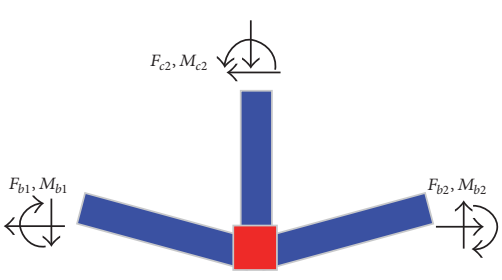

(c) Collapse stage

FIGURE 3: Element-deletion method.

division of line elements is needed to approximate the real displacement field, in order to improve the solution accuracy. The fine division of elements will increase the number of elements, which will affect the solution efficiency. To ensure the accuracy and efficiency of solution, flexibility-based fiber line element is used in this paper [19]. Sectional resistance and tangent stiffness of the flexibility-based beam-column elements are calculated by force function interpolation. Calculation is possible as long as the number of elements and the number of integration points are determined according to the dimensions of line members without the need to refine displacement field. In the nonlinear calculation process, good results can be obtained, and convergence is overall favorable.

Since the OpenSees program is different from the commercial finite element programs, if nonlinear dynamic analysis is performed by simply killing the predesigned key members applying "birth-death element" technology, the degree of freedom of the overall structure will undergo changes. Moreover, the instantaneous removal of elements leads to great dynamic effect on the structure, which is likely to result in interruption or nonconvergence of calculation process. In this paper, to achieve precise calculation, first of all, the overall calculation was conducted on the model, and the static internal force and counterforce of failure node were obtained. Then, the key components were removed and the static internal force and counterforce before the components were removed were exerted on the components at the same time so as to make the structure equal to the overall structure before the components were removed. Finally, to obtain the transient oscillation effect of the structure, the static internal force and counterforce on the key nodes were instantaneously removed, and the time was returned to zero at the same time for nonlinear dynamic calculation [20]. The schematic diagram of analytical procedure is shown in Figure 3.

Regarding iterative integration and solution, this paper employs Krylov-Newton algorithm to facilitate the convergence of program computation. Transformation method is used for boundary condition processing, while SparseSYM is utilized for solving dynamic analysis equations [21].

The SFI-MVLEM element is used as the shear wall element to calculate the elastoplastic behaviors of RC wall corresponding zones by taking into consideration the concrete confinement effect in the confinement zone of wall-edge members and the reinforcement assignment in the nonconfined zone of wall plates. Rebar is set according to the sectional design of members. Figure 4(a) shows the division of shear wall member elements, where the central joints and SFI-MVLEM elements are divided according to the shear wall height. In the figure, the modified ConcreteCM constitutive model is used for the concrete material, while the modified SteelMPF constitutive model is employed for the rebar material. The shear coefficient of element, dowel stiffness of rebar, 


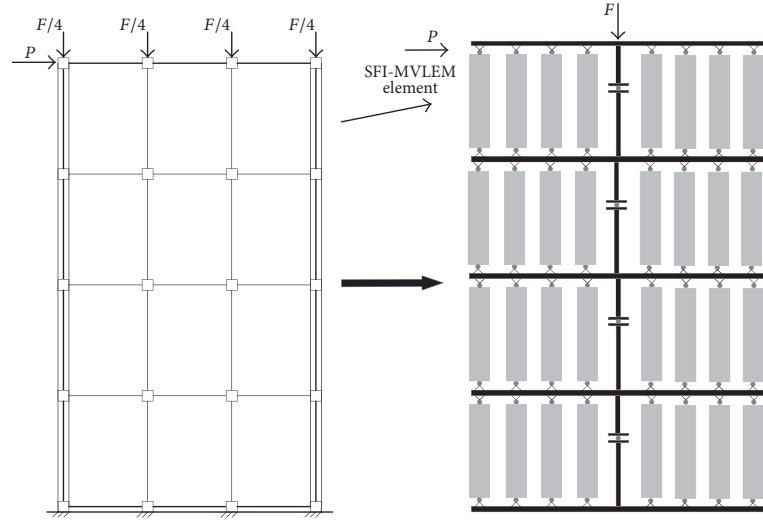

(a) Analysis model of shear wall

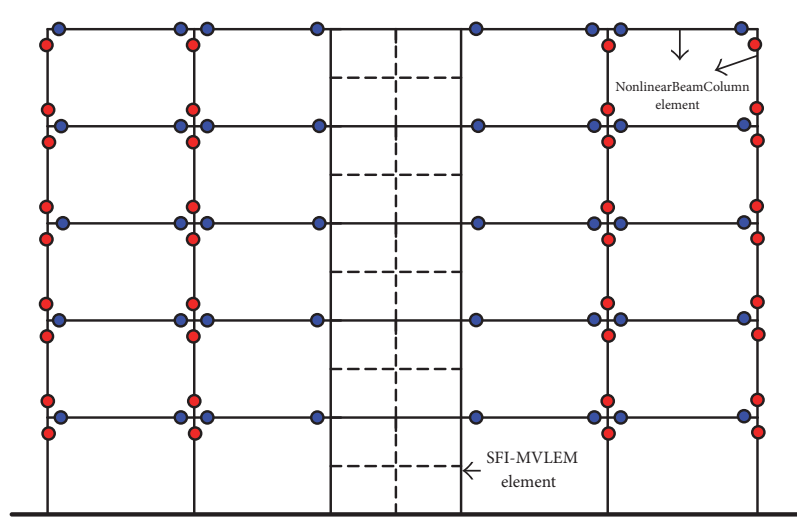

(b) Computational model

FIGURE 4: Finite element model.

and reinforcement ratio of members are calculated by applying the FSAM theory. The constitutive relations between concrete and rebar are integrated into a FSAM material constitutive model to perform the elastoplastic analysis of shear wall members. Finite elements of flexibility-based line system are modeled with the NonlinearBeamColumn element. Concrete is modeled using the Mander model, while rebar is modeled using the Giuffre-Gotto-Pinto model. For the models in this paper, two sets of shear wall elements are set up for each story taking the 5-story planar frame-shear wall structure as an example. Relevant schematic diagram is shown in Figure 4(b).

3.3. Validation of the Model with a Series of Test Results. Due to space constraints, four sets of shear wall specimens are selected in this paper for calculation with SFI-MVLEM shear wall elements, and the results are compared with the experimental data. The specific procedure is shown in Figure 5. Figure 5(a) [22] presents the linear shear wall with a design shear height ratio of 2.0. Experimental process is dominated by bending failure. Clearly, the calculated results of SFIMVLEM element are in good agreement with the experimental findings. Figure 5(b) presents the shear wall test with displacement ratio as the loading condition [23]. It can be concluded from the comparison results that the calculations in this paper are also applicable to shear walls controlled by this type of loads. Figure 5(c) shows the large-scale of shear wall specimen, where cracks spread through the wall plate area, and rebar at the bottom yield [24]. Comparison data demonstrates that the SFI-MVLEM element can well calculate the elastic-plastic behavior of such shear walls. Figure 5(d) shows the high-strength concrete shear wall member, whose concrete strength is up to $102 \mathrm{MPa}$ [25]. The model in this paper allows accurate calculation of such shear wall members. It can thus be concluded that the SFI-MVLEM shear wall element has a good accuracy and is simple to model, which is suitable for various kinds of complex shear wall members.

Ren et al. [26] from the Tsinghua University conducted a series of progressive collapse tests on beam-slab structure to consider the antiprogressive collapse performance of beamslab structure after failure of frame columns. During the tests, they analyzed the failure mechanism and resistance mechanism of floor system in the collapsing process of columns and discussed the contribution of floor slabs to the progressive collapse resistance of frame structure. Progressive collapse tests are simulated using the elements and modeling method presented in this paper. The calculation results are in good agreement with the experimental results, which well predict the experimental curves in the beam mechanism stage and the transition stage between beam and catenary mechanisms. Figure 6 presents the reinforcement drawing in the tests. The calculation results and the contrast data are shown in Figure 7.

In order to study the differences of the full-size experiment and reduced scale experiment of frame-shear wall structure in earthquake disaster, Japan and the United States cooperated a series of structural dynamic time history experiments. The full-scale structure was tested at the Large-Scale Testing Facility at the Building Research Institute (BRI) in Tsukuba, Japan. Then, Wolfgram [27] conducted three groups of reduced scale experiments. In the paper, one frame-shear wall structure experiment was selected for simulation. The calculation results are consistent with the displacement time history curve of the structure experiment test and can satisfy the needs of the research (Figure 8).

\section{Nonlinear Dynamic Analysis of Frame-Shear Wall Structure}

4.1. Demolition of Bottom Corner Columns. Figure 9 shows the comparisons of vertical displacement time histories between nodes of structure stories after corner column failure. By comparing with the analysis results of various frameshear structures in this paper, we find that all the three structures have not undergone collapse behavior after demolition of bottom short-side corner column. Besides, vertical displacements at the short-side frame beam are small, all of which reached the free vibration within $1 \mathrm{~s}$ into a steady state. 


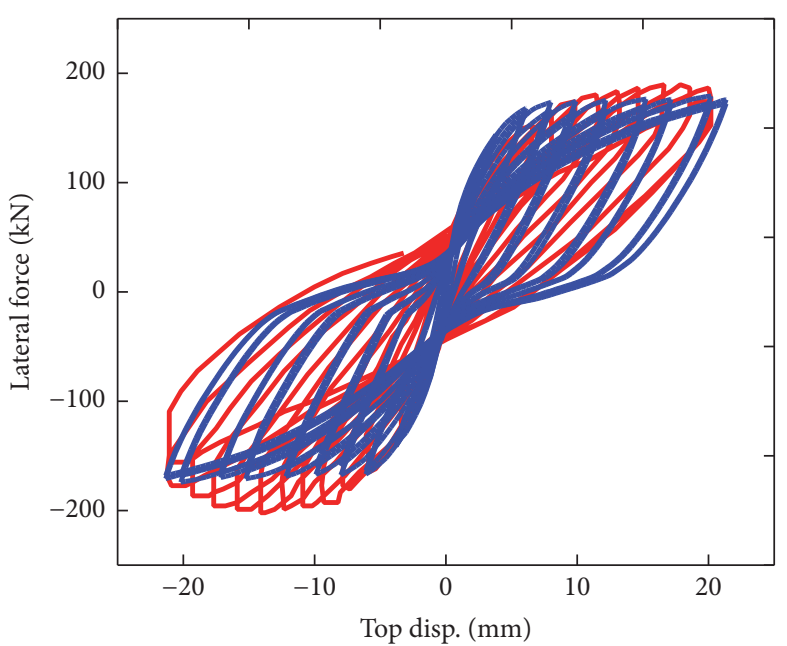

— Test

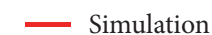

(a) SW1-1

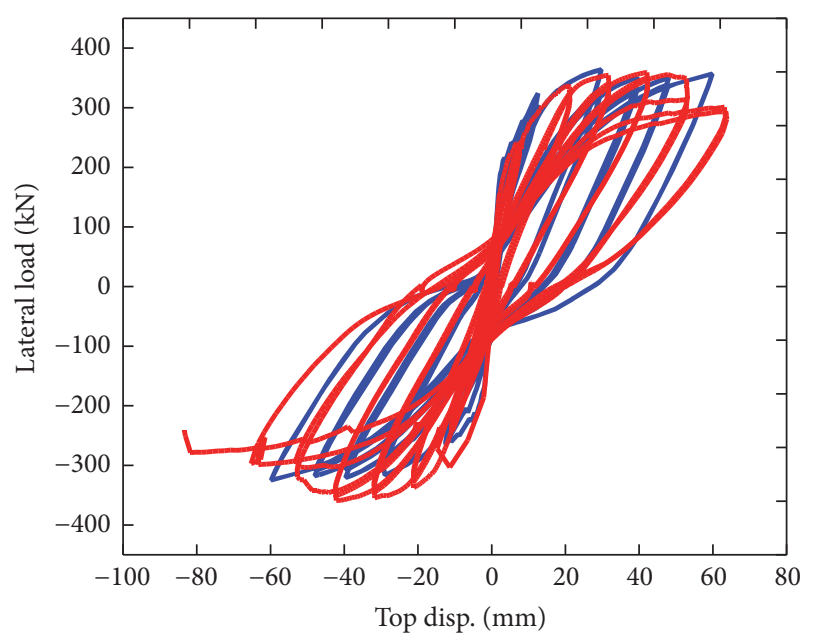

Test
- Simulation

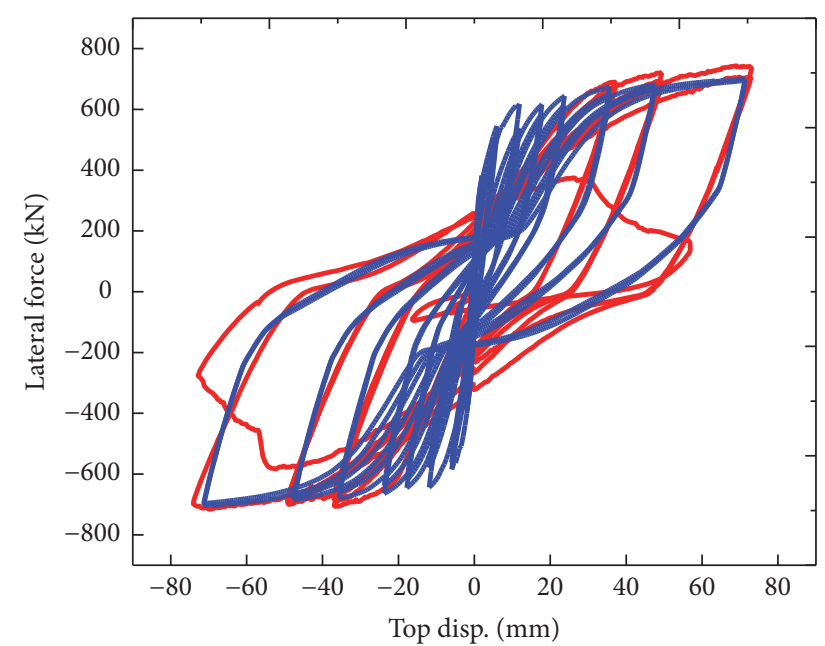

— Test
- Simulation

(b) SW2-2

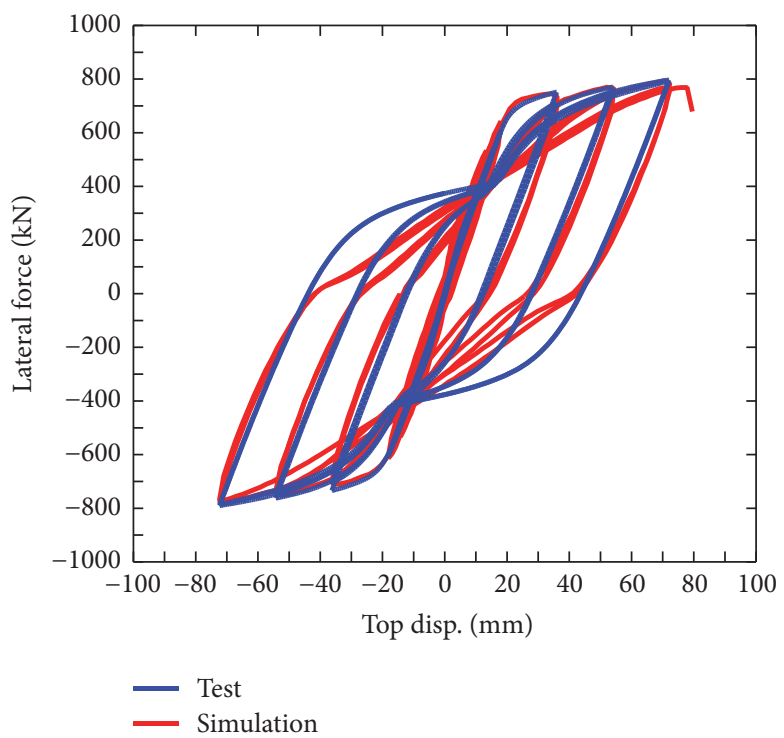

(d) SW4-4

Figure 5: Top force versus displacement hysteretic curve of specimens.

Comparison of the displacement time history curves between various structures reveals that after demolition of corner column the top displacement at demolition site of 10-story frame-shear structure is at the highest level, which is about $1 / 100$ of the span of the long-side frame beam. The vertical displacement at the first story apex of 15-story structure is slightly smaller, which also does not satisfy the displacement judgment about structural progressive collapse. The 10-story frame-shear structure with seismic design exhibits the lowest displacement level. Its top displacement at demolition site is about $7.1 \mathrm{~mm}$ lower than the ordinary 10 -story structure. This is because, for the case of demolition of short-side corner column, the side frame originally supported by corner column turns into a cantilever beam, and the upper loads of structure gather towards the failure corner region. By strengthening the seismic design of structure, the seismic performance level is elevated compared to the ordinary structure. According to "strong column weak beam" design requirements in China, we can enhance the horizontal restraints at the structural beam ends and improve the stiffness and bearing capacity of nodes, while increasing the integrity of structure, thereby enhancing the ductility of high-level structure, so that the collapse resistance at the failure corner region maintains high level [28]. Thus, the vertical displacement at its failure apex is rather small. In addition, for the 15-story structure, the upper frame beam at the corner region creates a hollow rod effect after failure of bottom column, which generates new bending moment at beam ends in the form of gravity equiaxial pressure to dissipate the unbalanced work of superstructure. It can be seen by comparing the top displacement that the higher 


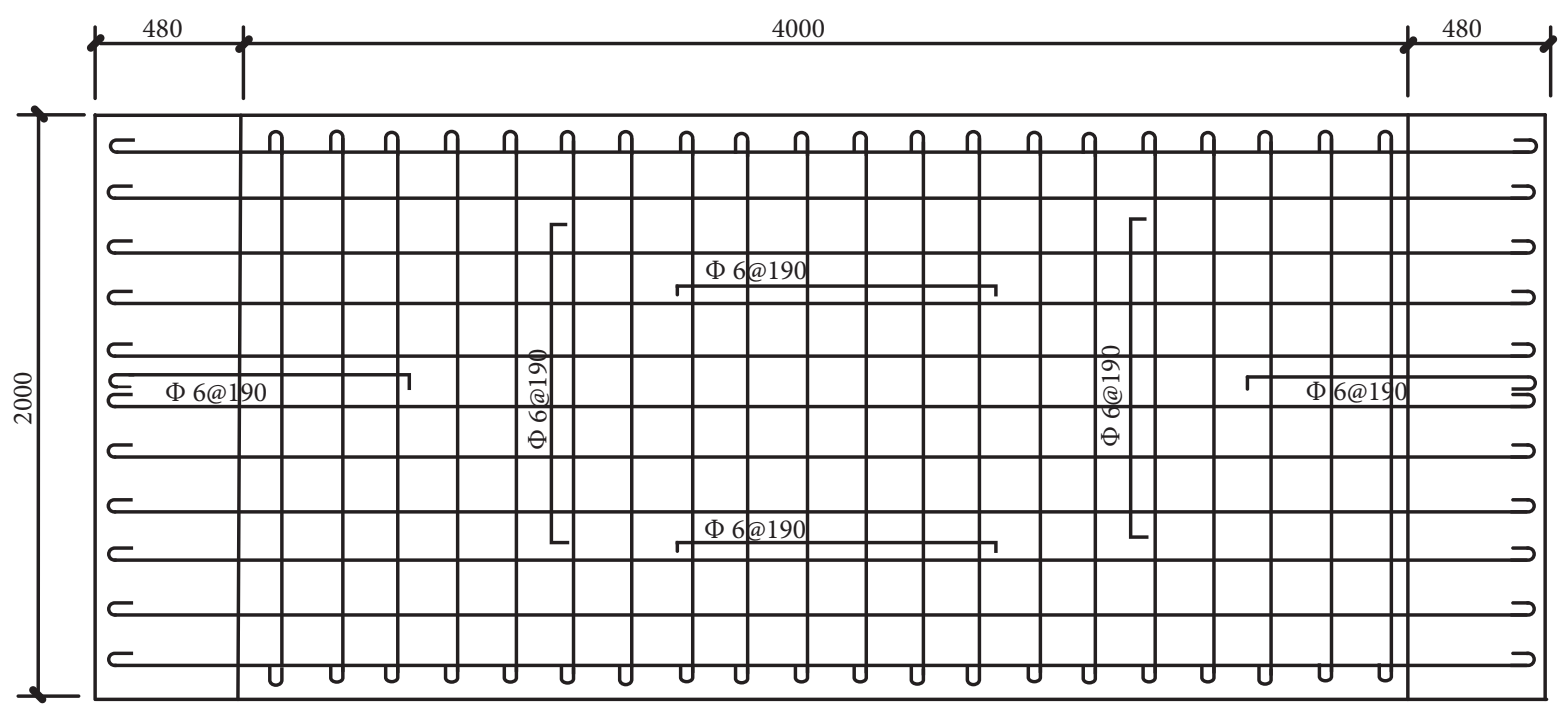

(a) Plate fitted with reinforcing bars

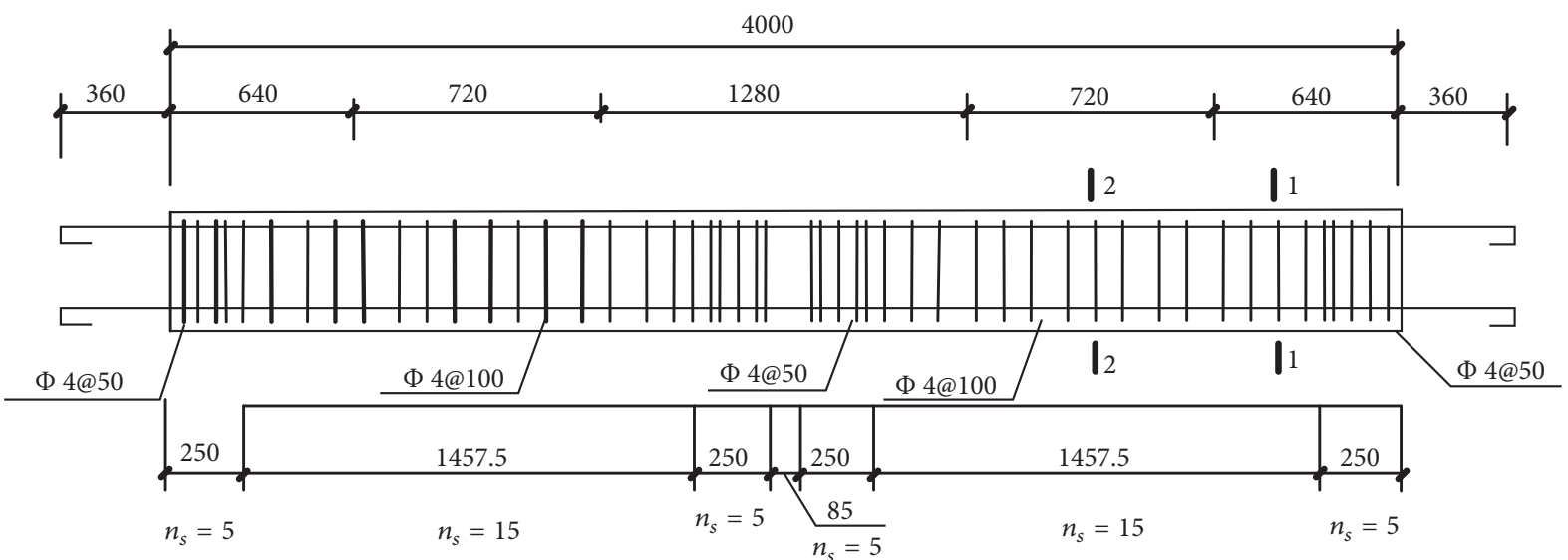

(b) $X$ direction cross section

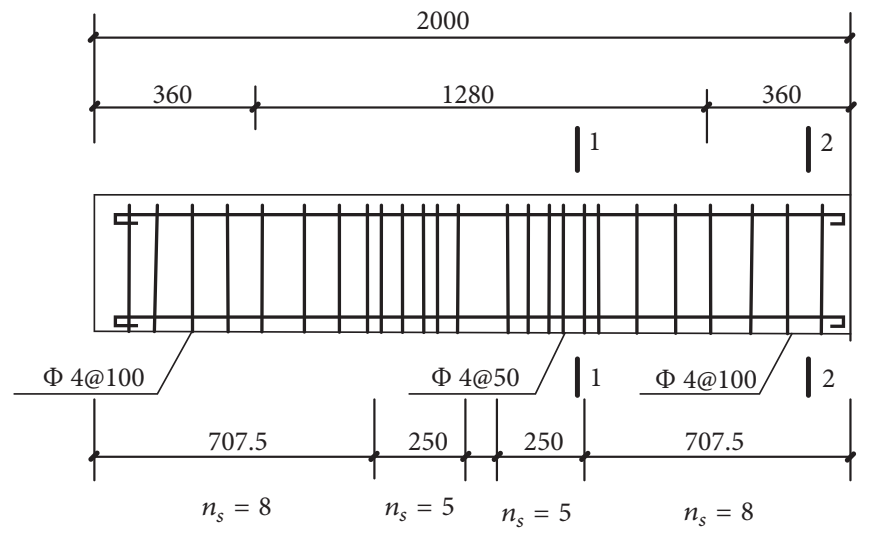

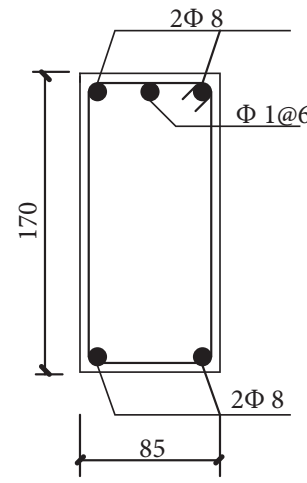

1-1 Section

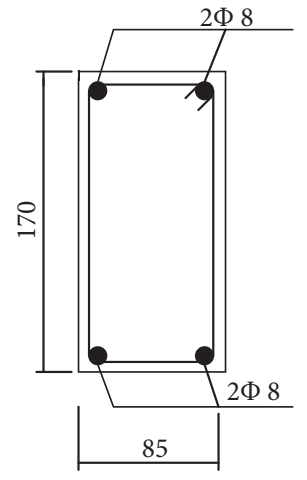

2-2 Section

(c) $Y$ direction cross section

FIgURE 6: Reinforce details of the RC frames.

the structure story, the better the hollow rod effect, but the smaller the contribution to collapse resistance. Meanwhile, in terms of top displacement, the time history curve of 15-story structure tends to flatten out and is less oscillatory.
4.2. Demolition of Central Shear Wall. Figure 10 presents the comparisons of time histories between nodes of structure stories after shear wall failure. After the failure of central shear wall, the C-shaped shear wall undergoes a slight deformation, 

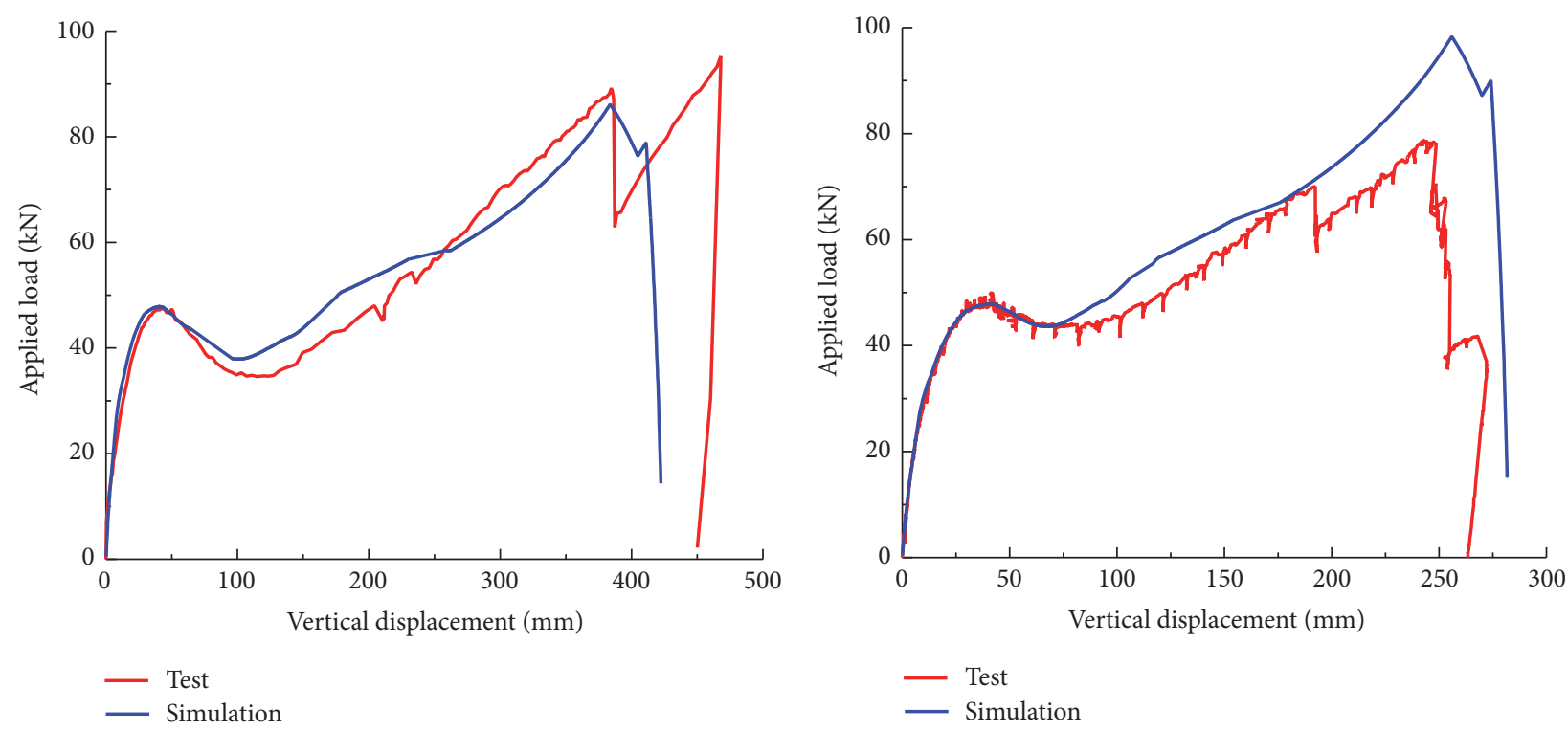

Figure 7: Comparisons between the numerical simulations and the test results.

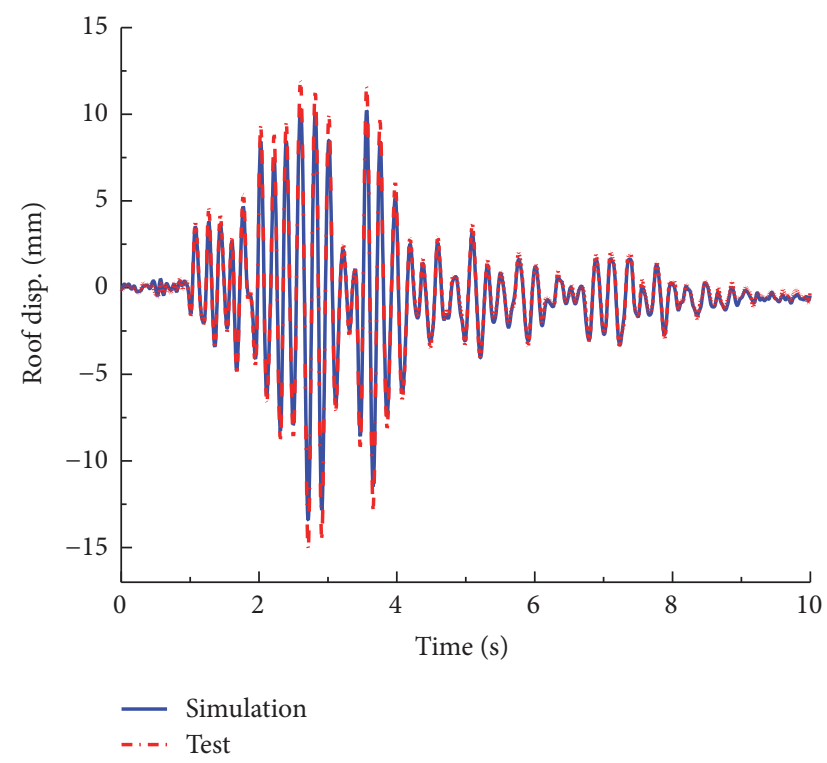

FIGURE 8: Comparisons between the numerical simulations and the test results.

and the structure basically has no risk of progressive collapse. By comparing the displacement time histories between various model nodes, we find that the first story node displacement of the 10-story frame-shear structure is at the highest level after failure of lateral shear wall. Its maximum vertical deformation is only $15.44 \mathrm{~mm}$. Meanwhile, no significant difference is found in the vertical displacement of nodes at the first story failure site between three models. Although the self-weight and bearing capacity of shear wall elements are higher than the frame columns and beams, the three shear walls form a C-shaped tube structure in this paper. When the central shear wall fails, the lateral and side shear walls can bear the unbalanced load of superstructure to become an effective alternative path. Meanwhile, the frame beamcolumn structure at the side of failed shear wall can provide the beam-end-beam mechanism collapse resistance contribution and the catenary mechanism anticollapse contribution of rebar tensile force within cross section to dissipate the unbalanced work within the structure, thereby improving the progressive collapse resistance $[29,30]$. As for the top story nodes, the apex of 15-story structure enters into the free vibration stabilization period within $1.5 \mathrm{~s}$. The vertical displacements of apexes are similar between the 10-story structures with or without seismic design. Finally, it can be seen that the structure of several floors (10,15 layers) and structure seismic design of 8 degrees (6 degrees) had slight effect on center shear wall failure in three sets of computing models due to the center position of shear wall and mechanical properties.

4.3. Demolition of Short Edge Columns Near the Center. Figure 11 shows the time history comparisons between nodes of structure stories after failure of short-side middle column. In contrast to the demolition of corner column, the demolition of short-side middle column causes the frame beams on three sides of column ends to become cantilever beams. From the comparison of vertical displacement curves between two cases, it is clear that the vertical displacements of nodes for the case of demolition of middle column frame-shear wall structure are generally smaller than the demolition of corner column. Among them, the maximum bottom node displacement of 10 -story structure is reduced by about $26 \%$, while the maximum bottom displacement of 15-story structure is reduced by about $28 \%$. This is caused by the lack of effective horizontal restraint protection for the frame beams at both vertical ends in the corner region after failure of corner support columns. The support column on the other side of frame beam can provide structural horizontal restraints, so 


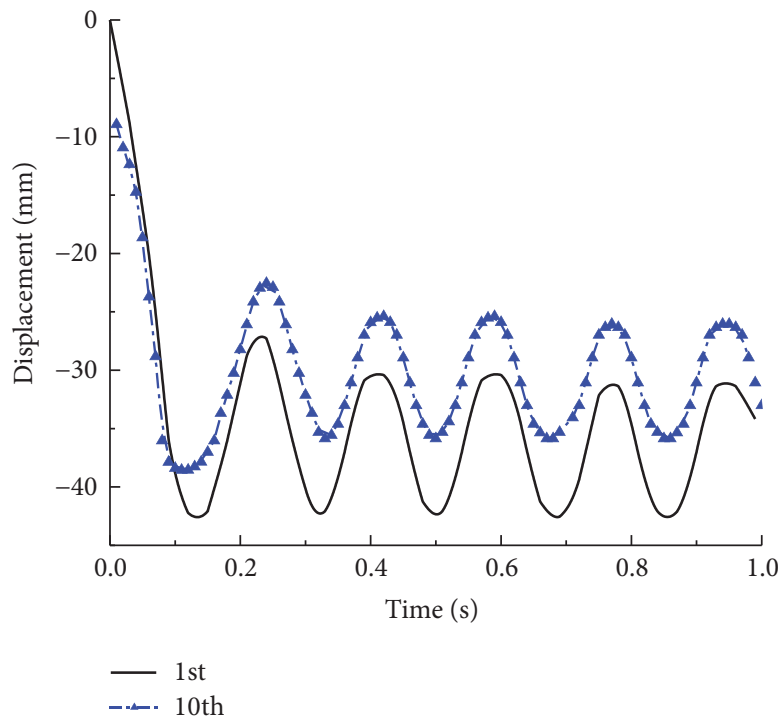

(a)

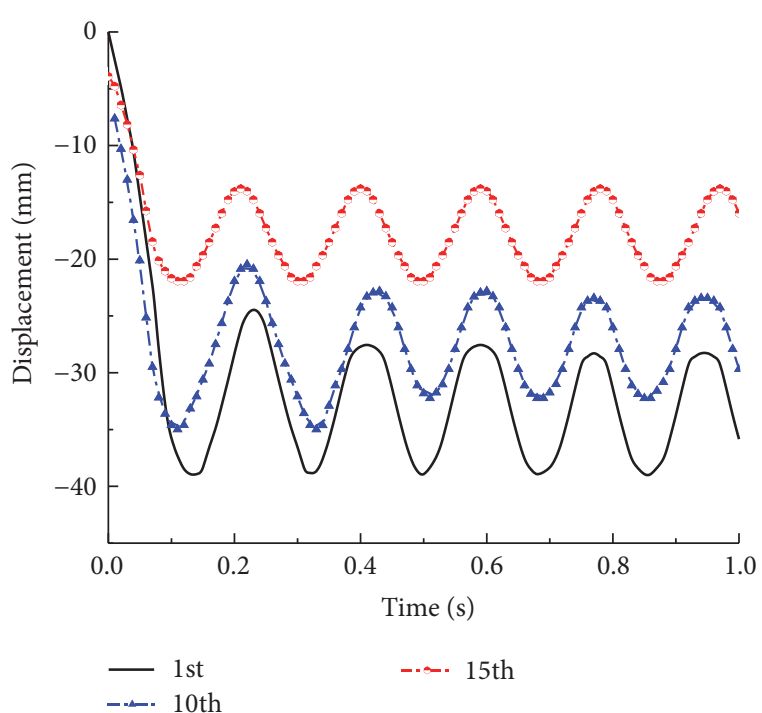

(b)

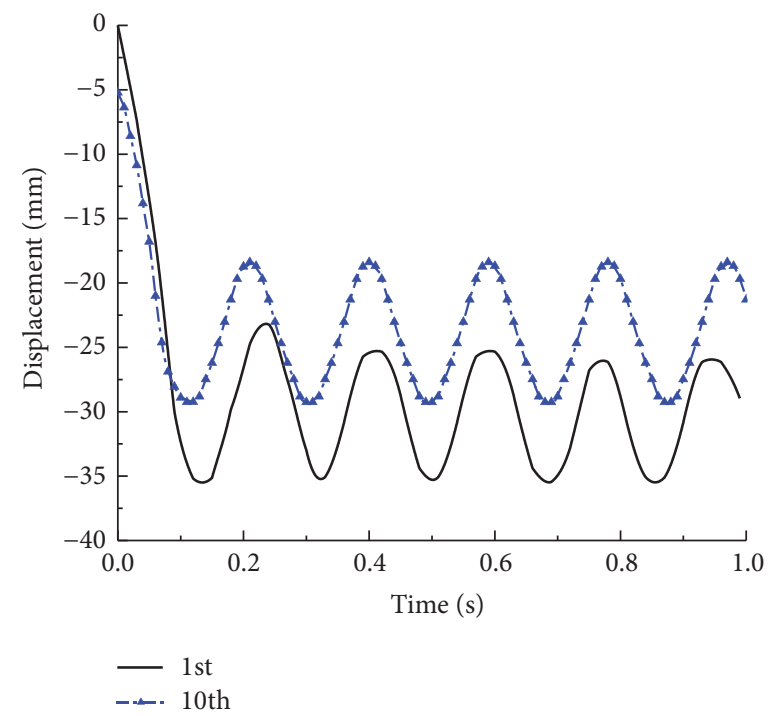

(c)

FIGURE 9: Removal of the corner columns in building: (a) 10-story model; (b) 15-story model; (c) 10-story model of the 8-degree seismic design; (a)-(c) vertical displacement of the joint at the top of the removed column on the $x$ th-story.

that pressure arch effect emerges within the beam to form the beam mechanism, which provides progressive collapse resistance in a manner that the ends of vertical two-way frame beams are subjected to bending loads. In the case of demolition of short-side middle column, horizontal restraints are provided by the support columns at frame beam ends after failure of middle column. The ends of three side frame beams form a beam mechanism to resist the collapse force by the end bending moments. Meanwhile, the $Y$-direction through frame beam in the periphery of structure can provide effective horizontal constraints, so that the beam can play a role of intrabeam rebar tensile force under large deformation to form catenary effect and to provide progressive collapse resistance. Thus, node deformations are generally small after failure of middle column. In addition, in the case of short-side middle column failure, the vertical deformations of bottom nodes for the 10-story frame structure with 8-degree seismic design are small, whose maximum node displacement is reduced by $23 \%$ compared to the ordinary 10 -story structure. This large vertical deformation is manifested basically the same as the case of corner column failure, indicating that the seismic design can effectively enhance the progressive collapse resistance of high-rise structures and improve the structural safety. Finally, it can be seen that in the case of short-side middle column failure, the structure with higher stories has little effect on the progressive collapse resistance under hollow rod effect. 


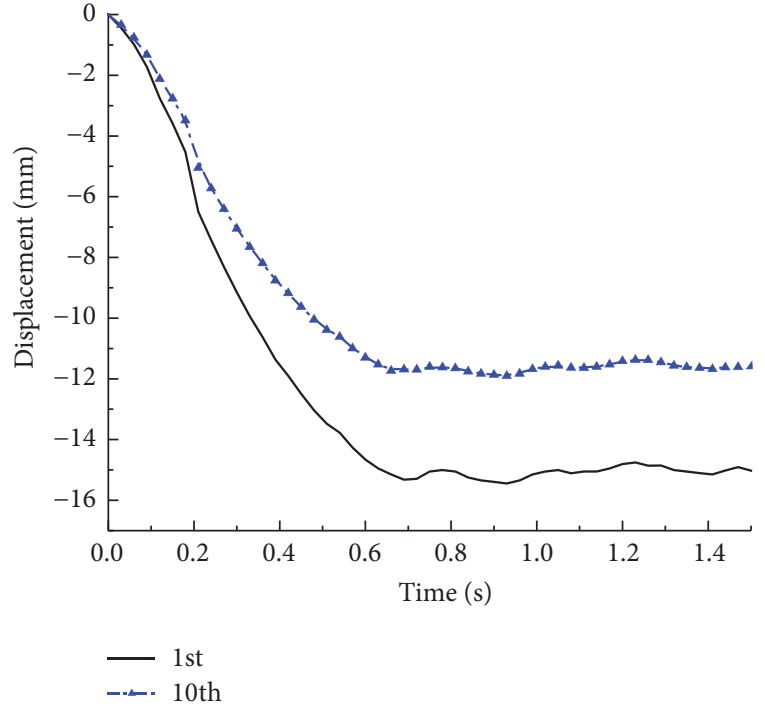

(a)

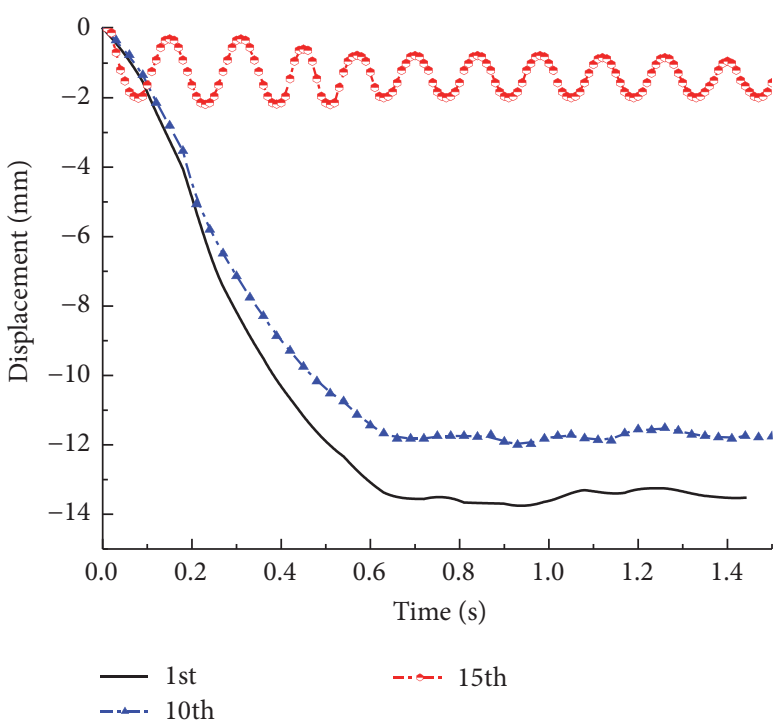

(b)

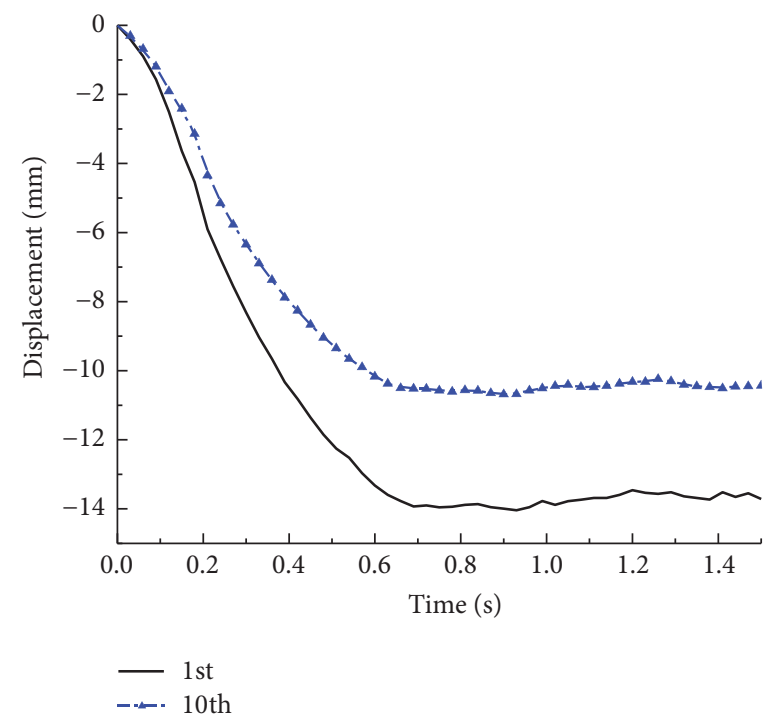

(c)

FIGURE 10: Removal of central shear wall in building: (a) 10-story model; (b) 15-story model; (c) 10-story model of the 8-degree seismic design; (a)-(c) vertical displacement of the joint at the top of the removed column on the $x$ th-story.

\section{Discussion on Anticollapse Design of Structures}

With the development of economy, high-rise structures continue to spring up; progressive collapse resistance design of high-rise structures has been gaining increasing attention. Anticollapse designs are made abroad mainly in accordance with the US GSA2010 and DoD2010 design guidelines. In China, the primary references are the Code for Design of Concrete Structures and the Technical Specification for Concrete Structures of High-Rise Buildings before 2015. In 2015, the Code for Anticollapse Design of Building Structures is officially promulgated, which presents the member tying method, alternate path method, local reinforcement method, and relevant theoretical calculation methods. Moreover, methods of calculating beam mechanism and rebar catenary mechanism are also supplemented based on the research findings in recent years. In view of the complexity of collapse, the existing specifications and design criteria have not formed a complete technical standard system yet. Further research is needed to perfect the theoretical calculation method, failure judging criteria, collapse judgment, and design parameters.

(1) In recent years, the engineering community's understanding of the design of structural antiprogressive collapse lies in the mere anticollapse design of important buildings in accordance with the codes, while ignoring the influences of anticollapse design on the earthquake, fire, and other disaster resistance of structures. This does not meet the requirements on the establishment of multihazard prevention system. 


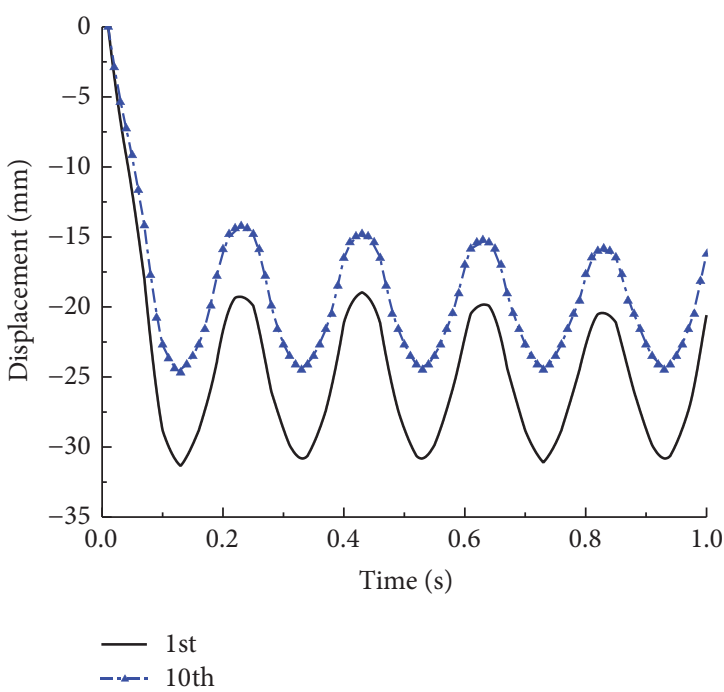

(a)

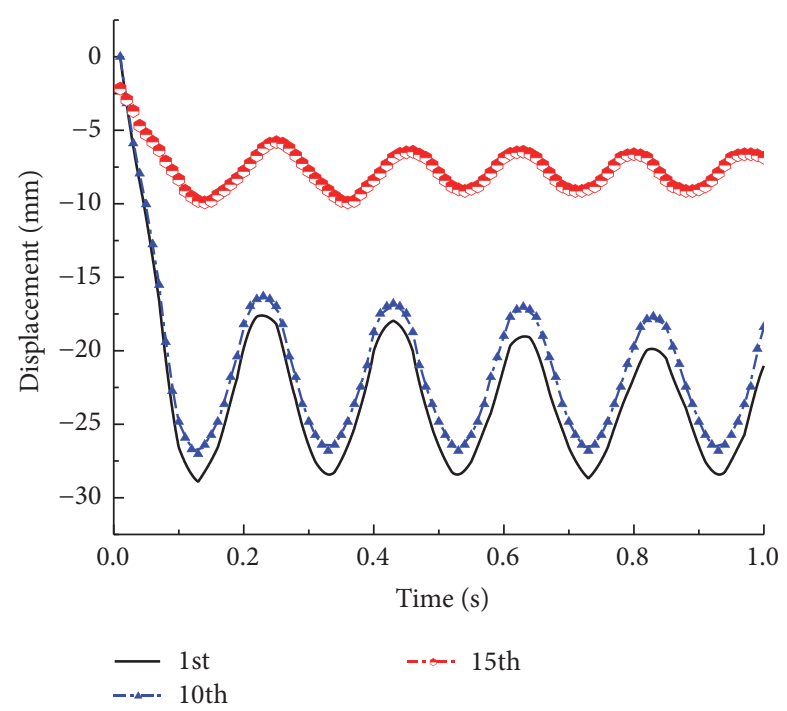

(b)

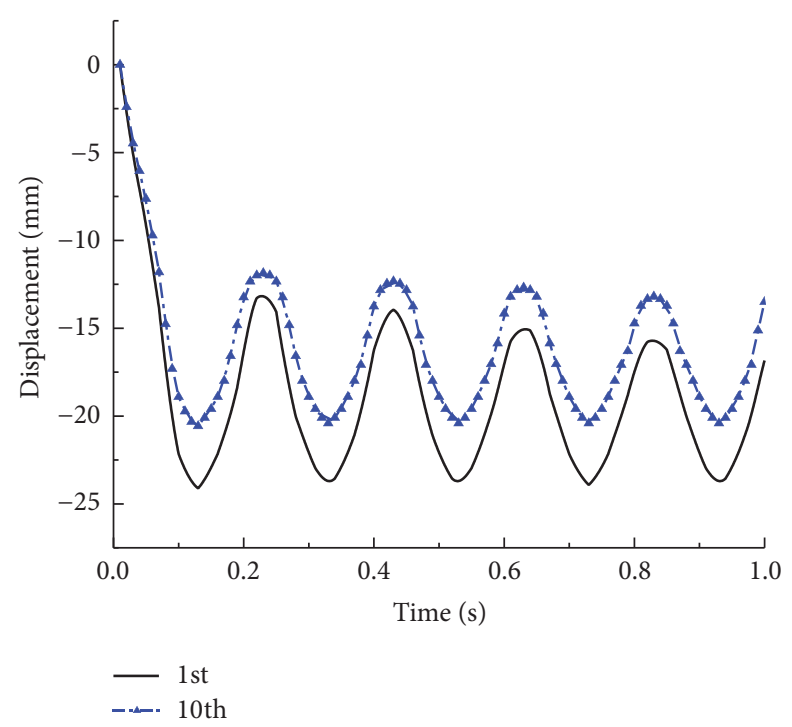

(c)

FIGURE 11: Removal of short-side middle column in building: (a) 10-story model; (b) 15-story model; (c) 10-story model of the 8-degree seismic design; (a)-(c) vertical displacement of the joint at the top of the removed column on the $x$ th-story.

For example, addition of intrabeam longitudinal reinforcement layout after the anticollapse design may result in "strong beam weak column" damage of the structure during the earthquake. In addition, with the increase of structural rebar, the impact on rebar increases under fire scenario, which may pose threats to the stability of high-rise structures. Therefore, for safety consideration, a secondary seismic or fireresistance design may be required after the anticollapse design. This means repeated design, which may result in increased material consumption and aggravated designer's responsibility. This paper attempts to discuss and analyze the structural progressive collapse using influencing factors such as seismic design and story number. We find that the direct seismic design of structure without collapse design can effectively improve its progressive collapse resistance. However, further in-depth study is needed, and design method suitable for seismic, fire, and progressive collapse resistance of high-rise structures needs to be put forward.

(2) Existing methods for anticollapse analysis of building structures mainly include the linear static alternate path method, nonlinear static alternate path method, linear dynamic alternate path method, and nonlinear dynamic alternate path method, of which the nonlinear dynamic alternate path method is the most accurate method for antiprogressive collapse analysis. Its analytical procedure is as follows: firstly, nonlinear numerical model of structure is constructed; key 
members are removed from top to bottom story-bystory, and nonlinear dynamic analysis is performed; if the structure undergoes progressive collapse and rebar in the collapse subarea is increased, then the demolition analysis cycle is continued until the structure no longer collapses. The method is computationally difficult to be widely used. Lu et al. [30, 31] modified the method by using a dynamic amplification factor (DAF) to correct the linear static resistance demand to approximate the true nonlinear dynamic resistance demand. They introduced dynamic method coefficient for considering dynamic response to calculate the dynamic internal force and to determine the design value of load effect and the nonlinear dynamic resistance requirements, so that the designers can choose within this range. Its significance is that it simplifies the cyclic procedure and calculation difficulty of the nonlinear dynamic analysis. Although the analytical results are not as accurate as the nonlinear dynamic method, it still meets the actual needs, so that ordinary designers can also perform the nonlinear design of anticontinuous structural collapse. More simplification attempts and innovative approaches are needed regarding the antiprogressive collapse analysis methods for building structures.

(3) Linear static alternate path method in GSA2010 mostly uses the internal force reduction coefficient and dynamic magnification factor to consider the dynamic response problem of structures. However, in practical engineering, nonlinear and dynamic factors will simultaneously produce effects on structure, which may lead to large computational error. Thus, progressive collapse specifications need to be further perfected and supplemented [32, 33].

(4) Parameter settings in the codes for progressive collapse resistance design are mostly based on the previous collapse disaster data, which are highly occasional. Besides, testing of large-scale structures is costly, demanding in terms of test platform, data collection, and testing personnel, and makes verification of design parameters difficult. In additions, the current structural theory and building material performance are all significantly better than the past, which will thus lead to certain errors in the calculation of parameters.

\section{Conclusion}

Through the above nonlinear progressive collapse analysis of high-rise frame-shear structures, we can draw the following conclusions:

(1) Nonlinear finite element model of high-rise frameshear structure is built by using the novel shear wall element SFI-MVLEM and the flexible line fiber element. The feasibility of simulating progressive structural collapse with SFI-MVLEM and line flexibility elements is verified via collapse tests on substructures comprising four shear wall members and two frame sets as an example. Meanwhile, the use of progressive collapse analysis method and the integral iteration and solution methods proposed in this paper can well obtain the progressive collapse analysis data of structures. This indicates that the finite element program OpenSees can be applied to the seismic and progressive collapse analyses of large-scale high-rise structures.

(2) Considering the effects of story number and seismic design on the structural progressive collapse resistance in the high-rise frame-shear structures, three typical cases are designed for the nonlinear collapse analysis of high-rise structures. The results show that the frame-shear structure has a fairly complete transmission path upon initial failure of the corner column to prevent collapse behavior. When the shear wall produced initial damage, shear wall edge frame beams formed anticollapse strength at end bending moment; the reinforcing steel bar in the beam provided catenary mechanism in the form of tension, formed anticollapse strength and connected with the wall around the ones where shear failed, and could effectively alter force transferring path, so it could effectively resist continuity of collapse, and frame-shear wall structure had small deformation. In the case of short-side middle column failure, the structural vertical deformation is smaller than the corner column failure. Finally, anticollapse performance of high-rise structures is well improved after 8-degree seismic design.

\section{Conflicts of Interest}

The authors declare that they have no conflicts of interest.

\section{References}

[1] X. Z. Lu, Y. Li, and L. P. Ye, Theory and Design Method for Progressive Collapse Prevention of Concrete Structures, China Architecture \& Building Press, Beijing, China, 2011.

[2] M. Sasani, M. Bazan, and S. Sagiroglu, "Experimental and analytical progressive collapse evaluation of actual reinforced concrete structure," ACI Structural Journal, vol. 104, no. 6, pp. 731739, 2007.

[3] L. Kwasniewski, "Nonlinear dynamic simulations of progressive collapse for a multistory building," Engineering Structures, vol. 32, no. 5, pp. 1223-1235, 2010.

[4] P. X. Dat and T. K. Hai, "Membrane actions of RC slabs in mitigating progressive collapse of building structures," Engineering Structures, vol. 55, pp. 107-115, 2013.

[5] United States General Services Administration (GSA), Progressive Collapse Analysis and Design Guidelines for New Federal Office Buildings and Major Modernization Projects, United States General Services Administration (GSA), Washington, DC, USA, 2010.

[6] Department of Defense (DoD), Unified Facilities Criteria (UFC): Design of Structures to Resist Progressive Collapse, Department of Defense, Washington, DC, USA, 2010. 
[7] China Engineering Construction Standardization Association (CECS), "Code for anti-collapse design of building structures," CECS 392:2014, China Engineering Construction Standardization Association (CECS), Beijing, China, 2014.

[8] W.-J. Yi, Q.-F. He, Y. Xiao, and S. K. Kunnath, "Experimental study on progressive collapse-resistant behavior of reinforced concrete frame structures," ACI Structural Journal, vol. 105, no. 4, pp. 433-439, 2008.

[9] S. Li, S. Shan, C. Zhai, and L. Xie, "Experimental and numerical study on progressive collapse process of RC frames with fullheight infill walls," Engineering Failure Analysis, vol. 59, pp. 5768, 2016.

[10] S.-J. Wang, F.-S. Liu, and Z.-D. Xu, "Experimental and theoretical analyses on entire course of vertical progressive collapse of spatial RC frame structures," Engineering Mechanics, vol. 32, no. 5, pp. 162-177, 2015.

[11] L. M. Zhang and X. L. Liu, "Some issues in the collapse analysis of frame structures," Journal of Shang Hai Jiao Tong University, vol. 35, no. 10, pp. 1578-1582, 2003.

[12] A. G. Vlassis, B. A. Izzuddin, A. Y. Elghazouli, and D. A. Nethercot, "Progressive collapse of multi-storey buildings due to failed floor impact," Engineering Structures, vol. 31, no. 7, pp. 15221534, 2009.

[13] Y. Li, X. Lu, H. Guan, and P. Ren, "Numerical investigation of progressive collapse resistance of reinforced concrete frames subject to column removals from different stories," Advances in Structural Engineering, vol. 19, no. 2, pp. 314-326, 2016.

[14] W.-D. Wang, J.-X. Wang, and X.-Y. Zhou, "Nonlinear dynamic progressive collapse analysis of composite frames with concrete-filled steel tubular columns based on fiber model," Engineering Mechanics, vol. 31, no. 9, pp. 142-151, 2014.

[15] Ministry of Housing and Urban-Rural Development of the People's Republic of China (MOHURD), "Code for design of concrete structures," GB 50010-2010, Ministry of Housing and Urban-Rural Development of the People's Republic of China (MOHURD), Beijing, China, 2010.

[16] Ministry of Housing and Urban-Rural Development of the People's Republic of China (MOHURD), "Code for seismic design of buildings," GB 50011-2010, Ministry of Housing and Urban-Rural Development of the People's Republic of China (MOHURD), Beijing, China, 2010.

[17] T. Kabeyasawa, H. Shiohara, S. Otani et al., "Analysis of the fullscale seven-story reinforced concrete test structure," Journal of the Faculty of Engineering, University of Tokyo, vol. 84, pp. 203239, 1982.

[18] K. Kolozvari and J. W. Wallace, "Practical nonlinear modeling of reinforced concrete structural walls," ASCE Journal of Structural Engineering, vol. 142, no. 12, 2016.

[19] F. C. Filippou and A. Issa, "Nonlinear analysis of reinforced concrete frames under cyclic load reversals," EERC Report 88/12, Earthquake Engineering Research Center, Berkeley, Calif, USA, 1988.

[20] M. Talaat and K. M. Mosalam, "Modeling progressive collapse in reinforced concrete buildings using direct element removal," Earthquake Engineering and Structural Dynamics, vol. 38, no. 5, pp. 609-634, 2009.

[21] M. H. Scott and G. L. Fenves, "Krylov subspace accelerated newton algorithm: application to dynamic progressive collapse simulation of frames," Journal of Structural Engineering, vol. 136, no. 5, pp. 473-480, 2010.
[22] H. M. Zhang, Study on the Performance-Based Seismic Design Method for Shear Wall Structures, Tongji University, Shanghai, China, 2007.

[23] T. A. Tran and J. W. Wallace, "Cyclic testing of moderate-aspectratio reinforced concrete structural walls," ACI Structural Journal, vol. 112, no. 6, pp. 653-665, 2015.

[24] A. Dazio, K. Beyer, and H. Bachmann, "Quasi-static cyclic tests and plastic hinge analysis of RC structural walls," Engineering Structures, vol. 31, no. 7, pp. 1556-1571, 2009.

[25] R. Burgueño, X. Liu, and E. M. Hines, "Web crushing capacity of high-strength concrete structural walls: experimental study," ACI Structural Journal, vol. 111, no. 2, pp. 235-246, 2014.

[26] P. Ren, Y. Li, X. Lu, H. Guan, and Y. Zhou, "Experimental investigation of progressive collapse resistance of one-way reinforced concrete beam-slab substructures under a middle-columnremoval scenario," Engineering Structures, vol. 118, pp. 28-40, 2016.

[27] G. E. Wolfgram, Experimental modelling and analysis of three one-tenth-scale reinforced concrete frame-wall structures [Ph.D. thesis], University of Illinois at Urbana-Champaign, Champaign, Ill, USA, 1984.

[28] Y. Bao and S. K. Kunnath, "Simplified progressive collapse simulation of RC frame-wall structures," Engineering Structures, vol. 32, no. 10, pp. 3153-3162, 2010.

[29] P. Ren, Y. Li, H. Guan et al., "Progressive collapse resistance of two typical high-rise RC frame shear wall structures," Journal of Performance of Constructed Facilities, vol. 29, no. 3, Article ID 04014087, pp. 1-9, 2015.

[30] Y. Li, X. Lu, H. Guan, and L. Ye, "An improved tie force method for progressive collapse resistance design of reinforced concrete frame structures," Engineering Structures, vol. 33, no. 10, pp. 2931-2942, 2011.

[31] X. Lu, L. Xie, H. Guan, Y. Huang, and X. Lu, "A shear wall element for nonlinear seismic analysis of super-tall buildings using OpenSees," Finite Elements in Analysis and Design, vol. 98, pp. 14-25, 2015.

[32] S. Gerasimidis and J. Sideri, "A new partial-distributed damage method for progressive collapse analysis of steel frames," Journal of Constructional Steel Research, vol. 119, pp. 233-245, 2016.

[33] S. Gerasimidis, G. Deodatis, T. Kontoroupi, and M. Ettouney, "Loss-of-stability induced progressive collapse modes in 3D steel moment frames," Structure and Infrastructure Engineering, vol. 11, no. 3, pp. 334-344, 2015. 


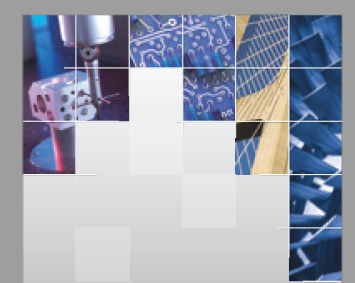

\section{Enfincering}
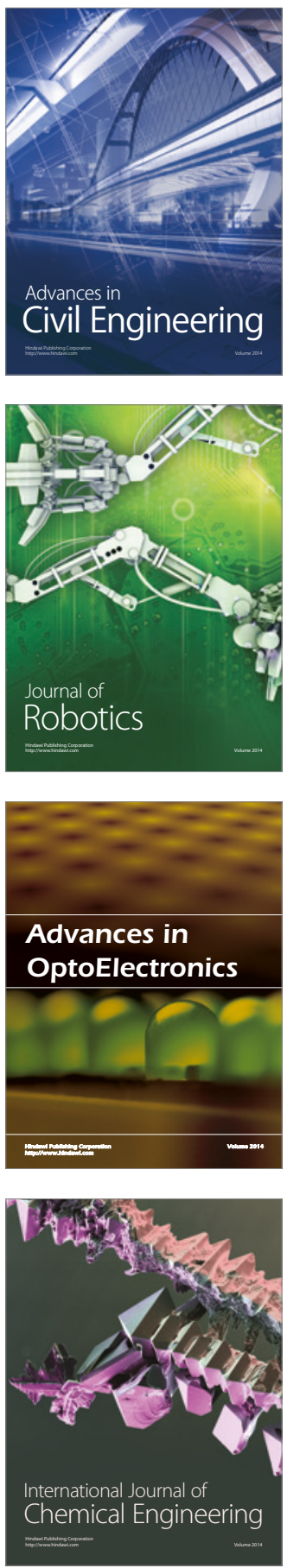

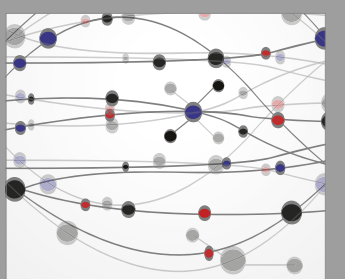

The Scientific World Journal

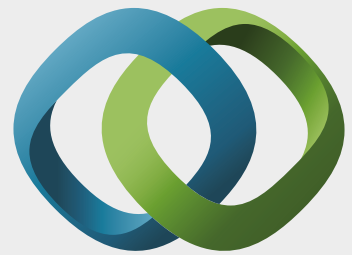

\section{Hindawi}

Submit your manuscripts at

https://www.hindawi.com
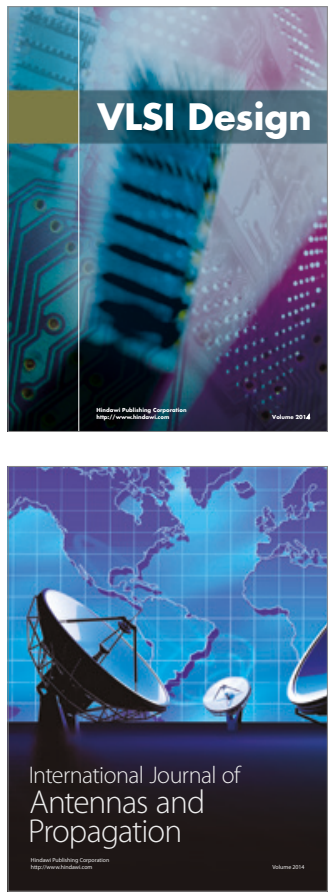

\section{Rotating}

Machinery
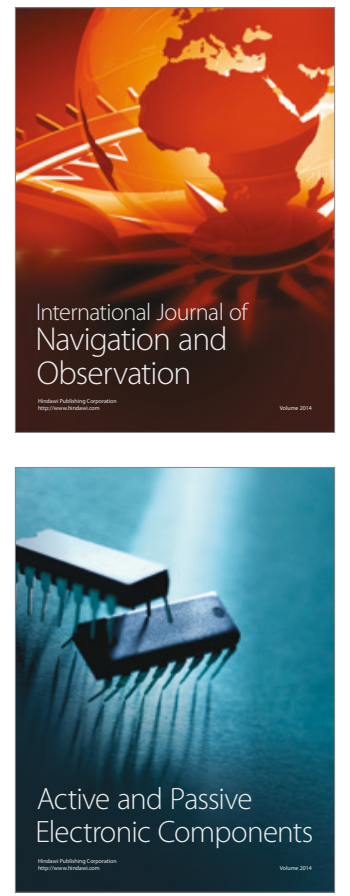
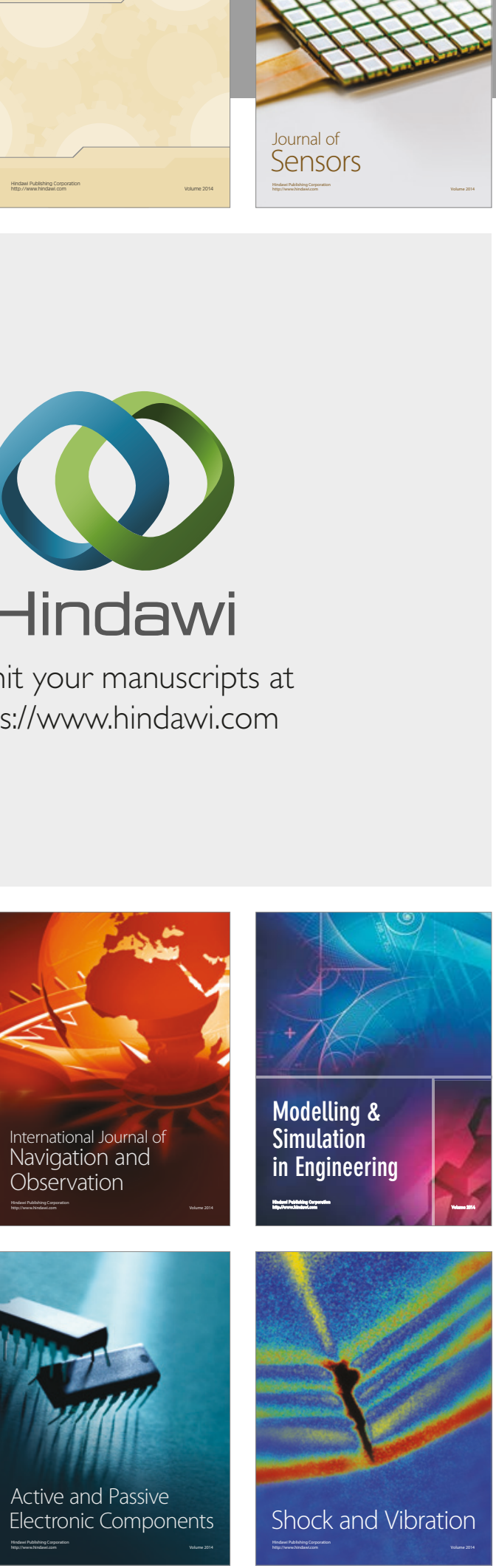
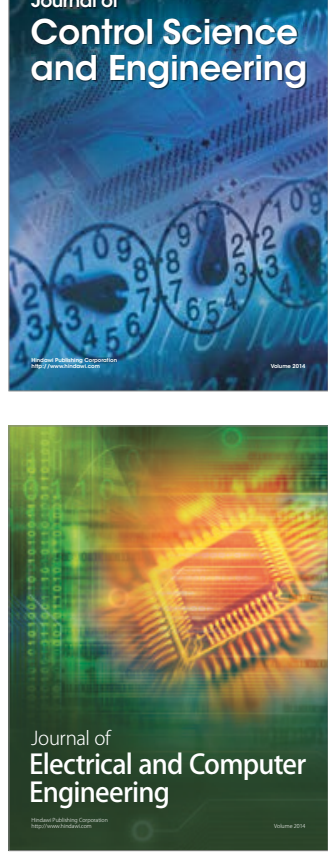

Distributed

Journal of

Control Science

and Engineering
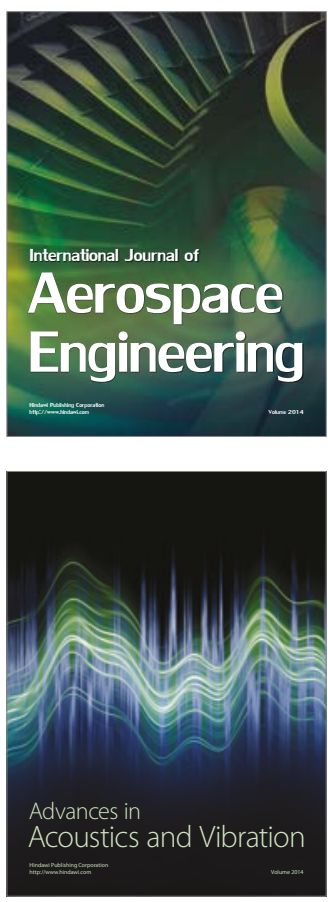

Sensor Networks 